\title{
Rotational Spectrum of the Most Abundant Isotopomers of the Van der Waals Dimer $\mathrm{N}_{2} \cdots \mathbf{H B r}$
}

\author{
Z. Kisiel, B.A. Pietrewicz and L. Pszczółkowski \\ Institute of Physics, Polish Academy of Sciences \\ al. Lotników 32/46, 02-668 Warszawa, Poland
}

(Received November 17, 2001)

\begin{abstract}
The rotational spectrum of the two most abundant isotopomers of the weakly bound dimer between dinitrogen and hydrogen bromide, ${ }^{14} \mathrm{~N}_{2} \cdots \mathrm{H}^{79} \mathrm{Br}$ and ${ }^{14} \mathrm{~N}_{2} \cdots \mathrm{H}^{81} \mathrm{Br}$, has been measured for the first time. The three lowest $J$ transitions, at frequencies from 2 to $8 \mathrm{GHz}$, have been studied at conditions of supersonic expansion. The complicated hyperfine splitting structure arising from the three non-equivalent quadrupolar nuclei has been assigned and fitted. The resulting spectroscopic constants and the derived molecular quantities are compared with those for other isotopomers, as well as with experimental and calculated results for other linear dimers involving dinitrogen. A revised value for the nuclear quadrupole splitting constant for free nitrogen molecule, $\chi(\mathrm{N})=-5.3(1) \mathrm{MHz}$, is also derived.
\end{abstract}

PACS numbers: 33.15.Dj, 33.15.Mt, 33.15.Pw, 33.20.Bx, 36.40.Mr

\section{Introduction}

The studies of small molecular clusters isolated at conditions of supersonic expansion continue to provide a plethora of detailed information on the nature of intermolecular interaction. Following extensive studies of dimeric species, the number of studies of clusters containing more than two molecules is steadily increasing. Of particular interest is the series of clusters consisting completely [1,2] or largely of water molecules [3], since they have a bearing on the important processes taking place in aqueous solutions, such as protolytic dissociation [4]. We have recently investigated in detail the first two members of the $\left(\mathrm{H}_{2} \mathrm{O}\right)_{n} \mathrm{HCl}$ family of clusters [5-7], and are currently in the process of studying their $\left(\mathrm{H}_{2} \mathrm{O}\right)_{n} \mathrm{HBr}$ analogues, 
namely $\mathrm{H}_{2} \mathrm{O} \cdots \mathrm{HBr}[8]$ and $\left(\mathrm{H}_{2} \mathrm{O}\right)_{2} \mathrm{HBr}[7,9]$. In such studies the knowledge of other intermolecular species which may be present as contaminants is a prerequisite. One of such species is $\mathrm{N}_{2} \cdots \mathrm{HBr}$, which is itself a member of an interesting family of clusters of potential stratospheric relevance. This dimer is expected to be routinely visible in the most popular supersonic expansion conditions using Ar carrier gas, since there is always some contamination of the carrier with nitrogen. The complex contains three non-equivalent quadrupolar nuclei and, as a consequence, the rotational spectrum exhibits rather complicated hyperfine splitting patterns. Hence, even though $\mathrm{N}_{2} \cdots \mathrm{HBr}$ has already been observed by rotational spectroscopy [10], only the isotopomers containing one or two ${ }^{15} \mathrm{~N}$ nuclei were investigated, since in those cases the hyperfine splitting was considerably simplified owing to the zero nuclear spin of ${ }^{15} \mathrm{~N}$. In this paper we report the observation and analysis of the most populated isotopomers of $\mathrm{N}_{2} \cdots \mathrm{HBr}$ in natural abundance, i.e. ${ }^{14} \mathrm{~N}_{2} \cdots \mathrm{H}^{79} \mathrm{Br}$ and ${ }^{14} \mathrm{~N}_{2} \cdots \mathrm{H}^{81} \mathrm{Br}$.

\section{Experimental details}

The measurements were carried out with the pulsed supersonic nozzle, cavity Fourier transform microwave (FTMW) spectrometer at the Institute of Physics, Warsaw [11]. The spectra were observed on a gaseous mixture of about $1 \%$ each of $\mathrm{N}_{2}$ and $\mathrm{HBr}$ in $\mathrm{Ar}$ carrier gas, expanded from a backing pressure of $1.1 \mathrm{~atm}$. The
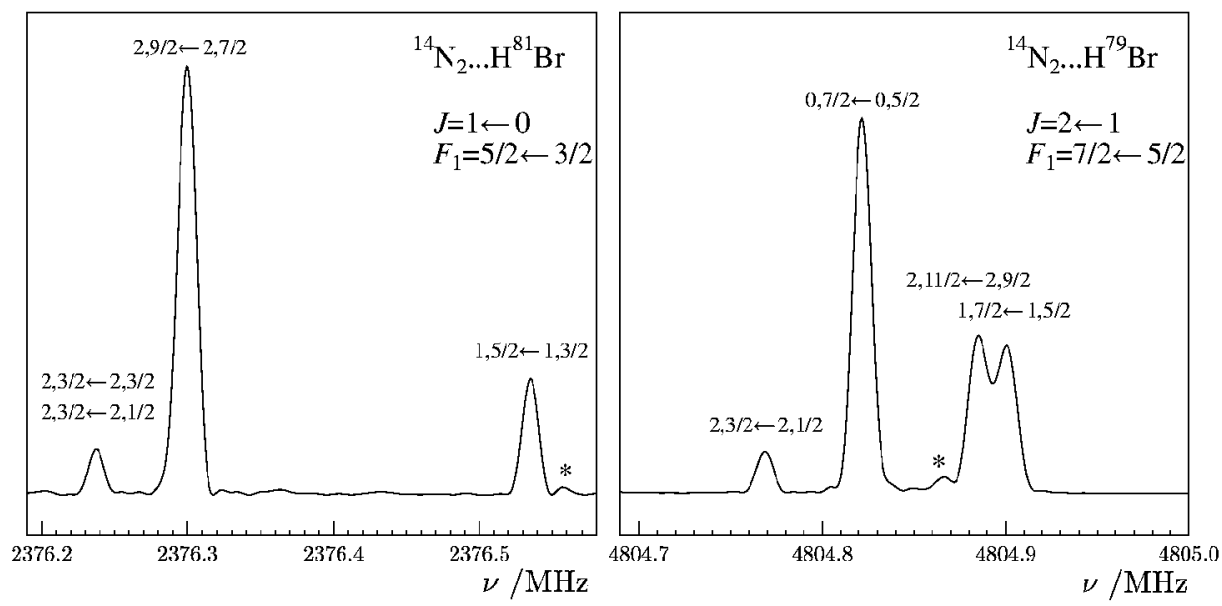

Fig. 1. Specimen spectra of the $J=1 \leftarrow 0$ and $J=2 \leftarrow 1$ rotational transitions of ${ }^{14} \mathrm{~N}_{2} \cdots \mathrm{HBr}$. The quantum numbers indicated above each transition are $I^{\prime}, F^{\prime} \leftarrow I^{\prime \prime}, F^{\prime \prime}$. The two transitions marked with asterisks have also been assigned, but they are not used in the fit since frequencies of such lines are usually strongly perturbed by the presence of dominant neighbours. 
gas mixture was pulsed into the high vacuum chamber containing the microwave cavity at a rate of $3 \mathrm{~Hz}$, and on expansion of each gas pulse eight independent microwave measurements were performed over a period of $1 \mathrm{~ms}$.

Although the spectrometer has been used in many previous studies, the present investigation provided an opportunity to test it near its lower frequency limit of operation. Such a limit is primarily determined by the size of the mirrors used in the microwave resonator, and in our spectrometer the mirrors are of $50 \mathrm{~cm}$ diameter. Thus the low-frequency limit of diminishing performance (Fresnel number of unity) is equal to $3.5 \mathrm{GHz}$. The two lowest $J$ transitions of $\mathrm{N}_{2} \cdots \mathrm{HBr}$ are somewhat more than $1 \mathrm{GHz}$ below and above this limit and the sensitivity obtained under normal conditions of a veraging of 100 to 500 multipulse interferograms is illustrated in Fig. 1. Very satisfactory performance has been obtained in both cases, although the interferogram recorded for the $J=1 \leftarrow 0$ transition is about 10 times weaker than that for $J=2 \leftarrow 1$. This is due to a factor of 4 ratio in spectroscopic intensity of the two transitions at the estimated $1 \mathrm{~K}$ expansion temperature, which is combined with a decrease in sensitivity due to diminishing performance of the microwave resonator.

\section{Results}

The rotational spectrum of $\mathrm{N}_{2} \cdots \mathrm{HBr}$ is that of an effectively linear molecule and transition frequencies of the parent isotopomers were predicted from the geometry and spectroscopic constants adapted from the ${ }^{15} \mathrm{~N}$ isotopomers observed in [10]. The analysis was based on the experience gained in our recent study of the most populated isotopomers of $\mathrm{N}_{2} \cdots \mathrm{HCl}$ [12]. The analysis of complicated spectroscopic problems of this type has been facilitated by the relatively recent availability to the spectroscopic community of several efficient computer codes. The fitting and prediction were performed with the SPFIT/SPCAT package of H.M. Pickett [13, 14], and graphical display of predictions for comparison with experiment was made with the program ASCP [15].

Figure 2 gives an overview of the key features of the rotational spectrum that have to be accounted for in the analysis. Each $J$ transition consists of several widely spaced dense multiplets, with multiplet spacing due to the large nuclear quadrupole splitting constants of the $\mathrm{Br}$ nuclei. The isotopic abundances of ${ }^{79} \mathrm{Br}$ and of ${ }^{81} \mathrm{Br}$ are comparable and, since the difference in rotational constants of the respective isotopomers is not very large, their rotational spectra are close together. Each of the dense multiplets has a complicated internal form due to the splitting from the two ${ }^{14} \mathrm{~N}$ nuclei, as visible in the expanded part of Fig. 2. The various angular momenta are most conveniently coupled using the $\left(F_{1}, I, F\right)$ scheme, as has been used for ${ }^{14} \mathrm{~N}_{2} \cdots \mathrm{HCl}$ [12]. The three hyperfine quantum numbers are therefore $F_{1}=J+I(\mathrm{Br}), I=I[\mathrm{~N}(1)]+I[\mathrm{~N}(2)], F=F_{1}+I$. 
$\mathrm{N}_{2} \ldots \mathrm{H}^{79} \mathrm{Br}$
$\ldots \ldots . .$.
$\mathrm{N}_{2} \ldots \mathrm{H}^{81} \mathrm{Br}$

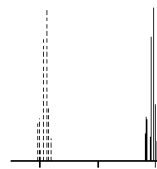

$\mathrm{MHz}$
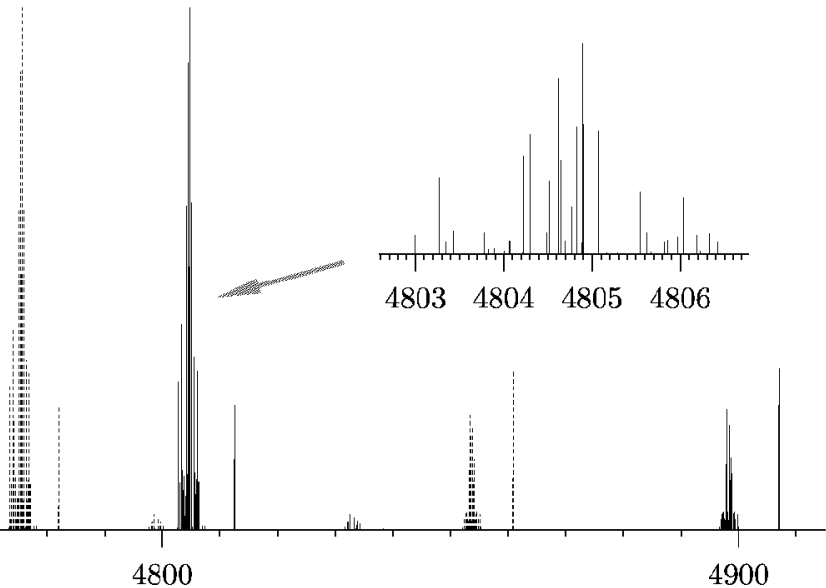

Fig. 2. Stick diagrams illustrating the main features of the hyperfine splitting patterns observed in ${ }^{14} \mathrm{~N}_{2} \cdots \mathrm{HBr}$.

TABLE I

Quantum number assignments, observed $(\mathrm{MHz})$, and observed-calculated $(\mathrm{o}-\mathrm{c})(\mathrm{kHz})$ frequencies for selected hyperfine components in the measured rotational transitions of ${ }^{14} \mathrm{~N}_{2} \cdots \mathrm{HBr}$.

\begin{tabular}{c|c|c|c|c|c|c|c|c|c}
\hline \hline & & & & & & \multicolumn{2}{|c|}{${ }^{14} \mathrm{~N}_{2} \cdots \mathrm{H}^{79} \mathrm{Br}$} & \multicolumn{2}{|c}{${ }^{14} \mathrm{~N}_{2} \cdots \mathrm{H}^{81} \mathrm{Br}$} \\
\cline { 5 - 9 } $2 F_{1}^{\prime}$ & $2 I^{\prime}$ & $2 F^{\prime}$ & $2 F_{1}^{\prime \prime}$ & $2 I^{\prime \prime}$ & $2 F^{\prime \prime}$ & obs. $/ \mathrm{MHz}$ & $\mathrm{o}-\mathrm{c} / \mathrm{kHz}$ & obs. $/ \mathrm{MHz}$ & $\mathrm{o}-\mathrm{c} / \mathrm{kHz}$ \\
\hline & & & & & & $J=1 \leftarrow 0$ & & & \\
5 & 4 & 5 & 3 & 4 & 7 & 2314.1763 & 0.2 & 2313.9438 & -2.2 \\
3 & 4 & 7 & 3 & 4 & 7 & 2388.5912 & 2.2 & 2376.2990 & 2.6 \\
\hline & & & & 4 & 7 & 2481.5254 & 1.4 & 2453.7633 & -0.5 \\
1 & 4 & 5 & 3 & 4 & 7 & $4645.1566^{a}$ & -10.1 & 4642.2858 & -0.4 \\
3 & 4 & 7 & 3 & 4 & 7 & 4739.6586 & 0.4 & 4721.0779 & -1.2 \\
7 & 4 & 11 & 5 & 4 & 9 & $4804.8942^{a}$ & 5.7 & 4775.7298 & -2.9 \\
1 & 4 & 3 & 1 & 4 & 5 & 4812.4981 & -2.0 & & \\
5 & 4 & 9 & 5 & 4 & 9 & 4898.0071 & 1.1 & 4853.4295 & -2.3 \\
\hline & & & & & & $J=3 \leftarrow 2$ & & & \\
3 & 4 & 7 & 3 & 4 & 7 & 7143.2157 & 1.6 & 7110.1448 & 0.6 \\
5 & 4 & 9 & 5 & 4 & 9 & 7171.5119 & -0.4 & 7133.4969 & 0.9 \\
7 & 4 & 7 & 5 & 4 & 5 & 7213.3684 & -0.2 & 7168.4634 & -0.2 \\
3 & 4 & 7 & 1 & 4 & 5 & 7237.7053 & -0.4 & 7188.9371 & -0.1 \\
7 & 4 & 11 & 7 & 4 & 11 & $7307.3937^{a}$ & -7.8 & 7247.0930 & 2.1 \\
\hline
\end{tabular}

a Transition excluded from the fit. 
The advantages of this coupling scheme are that the $F_{1}$ quantum number is equivalent to $F$ for the case of only the bromine nucleus being present, whereas the separate coupling of the small and very similar nuclear angular momenta of the two nitrogens improves numerical stability.

A selection of the measured transitions and their deviations from the fit is presented in Table I, and consists of some of the most prominent lines in each of the dense multiplets. The fitted spectroscopic constants are listed in Table II, where they are also compared with constants for the only two other known isotopomers containing ${ }^{14} \mathrm{~N}$. We have found, unlike in the case of ${ }^{14} \mathrm{~N}_{2} \cdots \mathrm{HCl}$, that it is not possible to determine independent values of nuclear quadrupole splitting constants for the two nitrogen nuclei. This is due to an almost unitary, negative correlation coefficient connecting these two constants. As a result their difference carries a very large error, which is comparable in magnitude to the value of the difference itself. On the other hand, the average of the two values is determined quite accurately. We believe that there are two principal reasons for this behaviour. The relative magnitudes of the nuclear angular momenta are such that there is a much greater decoupling of the bromine and of the nitrogen nuclear spins and that there are rather fewer of the various small accidental perturbations which normally aid in decorrelating coupling constants of this type. Furthermore we found that about a third of the measured lines exhibit systematic deviations from the fit made on the

TABLE II

The fitted spectroscopic constants and their errors ${ }^{a}$ (in brackets) for the four isotopomers of $\mathrm{N}_{2} \cdots \mathrm{HBr}$ containing the ${ }^{14} \mathrm{~N}$ nucleus.

\begin{tabular}{l|c|c|c|r}
\hline \hline \multirow{2}{*}{$B$} & ${ }^{14} \mathrm{~N}_{2} \cdots \mathrm{H}^{81} \mathrm{Br}$ & ${ }^{14} \mathrm{~N}_{2} \cdots \mathrm{H}^{79} \mathrm{Br}$ & ${ }^{14} \mathrm{~N}^{15} \mathrm{~N} \cdots \mathrm{H}^{79} \mathrm{Br}$ & ${ }^{15} \mathrm{~N}^{14} \mathrm{~N} \cdots \mathrm{H}^{79} \mathrm{Br}$ \\
\cline { 2 - 5 } & \multicolumn{2}{|c|}{ This work } & \multicolumn{2}{|c}{ Ref. $[10]$} \\
\hline$D_{J}(\mathrm{kHz})$ & $1195.55685(19)$ & $1203.16173(15)$ & $1181.6530(4)$ & $1163.2477(5)$ \\
\hline$\chi_{a a}(\mathrm{Br})(\mathrm{MHz})$ & $311.7525(31)$ & $373.1213(26)$ & $374.056(9)$ & $373.338(13)$ \\
$\chi_{a a}^{J}(\mathrm{Br})^{b}(\mathrm{kHz})$ & $2.09(37)$ & $3.41(37)$ & & \\
\hline$\chi_{a a}(\mathrm{~N})^{c}(\mathrm{MHz})$ & $-4.3397(13)$ & $-4.3383(11)$ & & \\
$\chi_{a a}[\mathrm{~N}(1)](\mathrm{MHz})$ & & & & $-4.302(7)$ \\
$\chi_{a a}[\mathrm{~N}(2)](\mathrm{MHz})$ & & & $-4.403(6)$ & \\
\hline$M_{b b}(\mathrm{Br})(\mathrm{kHz})$ & $-1.21(14)$ & $-1.36(14)$ & $-2.3(4)$ & $-1.9(5)$ \\
\hline$\sigma_{\text {fit }}(\mathrm{kHz})$ & 1.82 & 1.67 & & \\
lines fitted $^{d}$ & 62 & 56 & & \\
\hline$\sigma_{\text {The }}$ & & & & \\
\hline
\end{tabular}

${ }^{a}$ The reported uncertainties are standard errors in units of the last quoted digit.

${ }^{b}$ Centrifugal distortion contribution to $\chi_{a a}$ defined by $\chi(\mathrm{Br})=\chi_{a a}+\chi_{a a}^{J} J(J+1)$. ${ }^{c} \chi[\mathrm{N}(1)]=\chi[\mathrm{N}(2)]$, with nuclei in the order $\mathrm{BrH} \cdots \mathrm{N}(1) \mathrm{N}(2)$.

${ }^{d}$ The number of different frequency hyperfine components in the fit. 
basis of the usual $3 \sigma$ exclusion criterion, where $\sigma$ is the measurement uncertainty. The average magnitude of such deviations increases with $J$, reaching $c a .25 \mathrm{kHz}$ for $J=3 \leftarrow 2$, with the calculated frequencies being greater than the observed ones. This effect most probably results from the departure of the hyperfine splitting for shallow and highly anharmonic shallow intermolecular potentials from standard theory. A very large effect of this type has been observed for Ar $\cdots \mathrm{N}_{2}$ [16], where the authors were reduced to effective fits for each value of $K$. The $\mathrm{N}_{2} \cdots \mathrm{HBr}$ dimer is somewhat more strongly bound, but such deviations are still observable at the sub-Doppler resolution of our experiment. Sufficient noise is therefore introduced into transition frequencies to prohibit fitting of the rather subtle difference between the two nitrogen splitting constants. We have also tested the $\left(F_{1}, F_{2}, F\right)$ coupling scheme of the nuclear spins, as well as the $\left(F_{1}, F_{2}, F_{3}, F\right)$ quantization resulting from the effect of the spin of the hydrogen atom and of the very small magnitude spin-spin interactions that are possible. All of these alternative fits produced very similar results.

\section{Discussion}

The newly determined spectroscopic constants for ${ }^{14} \mathrm{~N}_{2} \cdots \mathrm{H}^{79} \mathrm{Br}$ and ${ }^{14} \mathrm{~N}_{2} \cdots \mathrm{H}^{81} \mathrm{Br}$ can be used to derive several quantities used to characterise the geometry, binding strength and internal dynamics in these dimers, as summarised in Table III. In determining the geometry it is crucial to realise that the two molecular units in the dimer undergo large amplitude oscillations relative to the inertial $a$-axis of the dimer, as described by average oscillation angles $\theta$ and $\phi$ for $\mathrm{N}_{2}$ and $\mathrm{HBr}$, respectively [10]. This has the consequence that the experimental properties, which are subject to averaging over the ground state wave function, are approximated by the averaging formula appropriate for the quantity [17]. The effective

TABLE III

Comparison of the derived quantities for the four isotopomers of $\mathrm{N}_{2} \cdots \mathrm{HBr}$ containing ${ }^{14} \mathrm{~N}_{2}$ and ${ }^{15} \mathrm{~N}_{2}$.

\begin{tabular}{l|c|c|c|c}
\hline \hline & ${ }^{14} \mathrm{~N}_{2} \cdots \mathrm{H}^{79} \mathrm{Br}$ & ${ }^{14} \mathrm{~N}_{2} \cdots \mathrm{H}^{81} \mathrm{Br}$ & ${ }^{15} \mathrm{~N}_{2} \cdots \mathrm{H}^{79} \mathrm{Br}$ & ${ }^{15} \mathrm{~N}_{2} \cdots \mathrm{H}^{81} \mathrm{Br}$ \\
\hline$\phi(\mathrm{HBr})^{a}(\mathrm{deg})$ & 25.11 & 25.10 & 25.00 & 24.99 \\
$\theta\left(\mathrm{N}_{2}\right)^{b}(\mathrm{deg})$ & 19.45 & 19.45 & 19.37 & 19.37 \\
\hline$r_{\mathrm{cm}}(\AA)$ & 4.4474 & 4.4477 & 4.4477 & 4.4480 \\
$r(\mathrm{~N} \cdots \mathrm{Br})(\AA)$ & 3.9450 & 3.9449 & 3.9452 & 3.9451 \\
\hline$f_{\sigma}\left(\mathrm{N} \mathrm{m}^{-1}\right)$ & 1.898 & 1.895 & 1.919 & 1.920 \\
$\epsilon\left(\mathrm{cm}^{-1}\right)$ & 263.8 & 263.4 & 267.0 & 267.1 \\
\hline
\end{tabular}

${ }^{a}$ Evaluated from the measured values of $\chi_{a a}(\mathrm{Br})$ and from the calculated field gradients.

${ }^{b}$ Evaluated from the effective $r_{s}$ bond length for complexed $\mathrm{N}_{2}$ determined from

${ }^{14} \mathrm{~N}$ or ${ }^{15} \mathrm{~N}$ isotopic substitution. 
bond lengths of the two subunits in the dimer are therefore given by $r_{0}^{\mathrm{N}_{2}} \cos \theta$ and $r_{0}^{\mathrm{HBr}} \cos \phi$, where $r_{0}^{\mathrm{N}_{2}}=1.1001 \AA$ and $r_{0}^{\mathrm{HBr}}=1.4243 \AA$ are ground state monomer bond lengths determined from their respective ground state rotational constants, $B_{0}\left({ }^{14} \mathrm{~N}_{2}\right)=59645.9(4) \mathrm{MHz}[18], B_{0}\left(\mathrm{H}^{79} \mathrm{Br}\right)=250358.51(15)$ and $B_{0}\left(\mathrm{H}^{81} \mathrm{Br}\right)=$ $250280.58(15) \mathrm{MHz}$ [19]. The intermolecular separation in the dimer is characterised by the distance between the centres of mass of the two monomers, $r_{\mathrm{cm}}$, given by

$$
I_{b}=\mu\left\langle r_{\mathrm{cm}}^{2}\right\rangle+\frac{1}{2} I_{b}^{\mathrm{N}_{2}}\left(1+\left\langle\cos ^{2} \theta\right\rangle\right)+\frac{1}{2} I_{b}^{\mathrm{HBr}}\left(1+\left\langle\cos ^{2} \phi\right\rangle\right),
$$

where $I_{b}, I_{b}^{\mathrm{N}_{2}}$, and $I_{b}^{\mathrm{HBr}}$ are ground state moments of inertia of the complex and of the two monomers, respectively, $\mu$ is the reduced mass, $\mu=M_{\mathrm{HBr}} M_{\mathrm{N}_{2}} /$ $\left(M_{\mathrm{HBr}}+M_{\mathrm{N}_{2}}\right)$, and angular brackets denote averages over the ground state wave function. The key interatomic distance $r(\mathrm{~N} \cdots \mathrm{Br})$ is then

$$
r(\mathrm{~N} \cdots \mathrm{Br})=\left\langle r_{\mathrm{cm}}^{2}\right\rangle^{1 / 2}-r_{\mathrm{cm}}^{\mathrm{N}}\langle\cos \theta\rangle+r_{\mathrm{cm}}^{\mathrm{Br}}\langle\cos \phi\rangle,
$$

where $r_{\mathrm{cm}}^{\mathrm{N}}$ and $r_{\mathrm{cm}}^{\mathrm{Br}}$ are distances of the $\mathrm{N}(1)$ and $\mathrm{Br}$ atoms from the centres of mass of their respective monomers, and atom ordering in the dimer is $\mathrm{BrH} \cdots \mathrm{N}(1) \mathrm{N}(2)$. The intermolecular stretching constant $f_{\sigma}$ is calculated from the centrifugal distortion constant $D_{J}$ by using the enhanced diatomic formula of Millen [20], which for $B / \mathrm{MHz}, D_{J} / \mathrm{kHz}, f_{\sigma} /\left(\mathrm{N} \mathrm{m}^{-1}\right), \mu / \mathrm{u}$ is

$$
f_{\sigma}=2.6222 \times 10^{-10} \frac{B_{0}^{3} \mu}{D_{J}}\left(1-B_{0} / B_{0}^{\mathrm{N}_{2}}-B_{0} / B_{0}^{\mathrm{HBr}}\right)
$$

where $B_{0}$ is the ground state rotational constant of the dimer. The well depth, $\epsilon$, of the intermolecular potential is calculated from the Lennard-Jones approximation [21] and, for $\epsilon / \mathrm{cm}^{-1}, r / \AA$, and $f_{\sigma} /\left(\mathrm{N} \mathrm{m}^{-1}\right)$

$$
\epsilon=503.412 f_{\sigma} r_{e}^{2} / 72
$$

where $r_{e}$ is intermolecular separation obtained by correcting intermolecular separation to the minimum in the approximating diatomic potential [21].

The large amplitude oscillation angles $\theta$ and $\phi$ for the two monomer molecules were derived using two different methods, which avoid the rather complicated iterative procedures employed in the original investigation [10]. We have taken advantage of the increasing ease of carrying out reasonably high level ab initio calculations and used calculated field gradients. The calculations were carried out with Dunning correlation consistent bases [22] and the GAMESS package [23]. Field gradients were evaluated at the aug-cc-pVTZ/MP2 level for the aug-cc-pVDZ/MP2 geometry. This level of calculation was found to be quite accurate for field gradients in $\left(\mathrm{H}_{2} \mathrm{O}\right)_{2} \mathrm{HCl}[6]$, and it has also been established that many features of field gradient calculations are relatively insensitive to the level of calculation [24]. The field gradients calculated for $\mathrm{N}_{2} \cdots \mathrm{HBr}$, several related dimers and the relevant monomers are reported in Table IV. The available experimental splitting constants are also tabulated therein. The scaling to compensate for the known 
TABLE IV

(A) Calculated field gradients (a.u.) and (B) measured nuclear quadrupole splitting constants $(\mathrm{MHz})$ for linear dimers of $\mathrm{N}_{2}$ and for the isolated monomers.

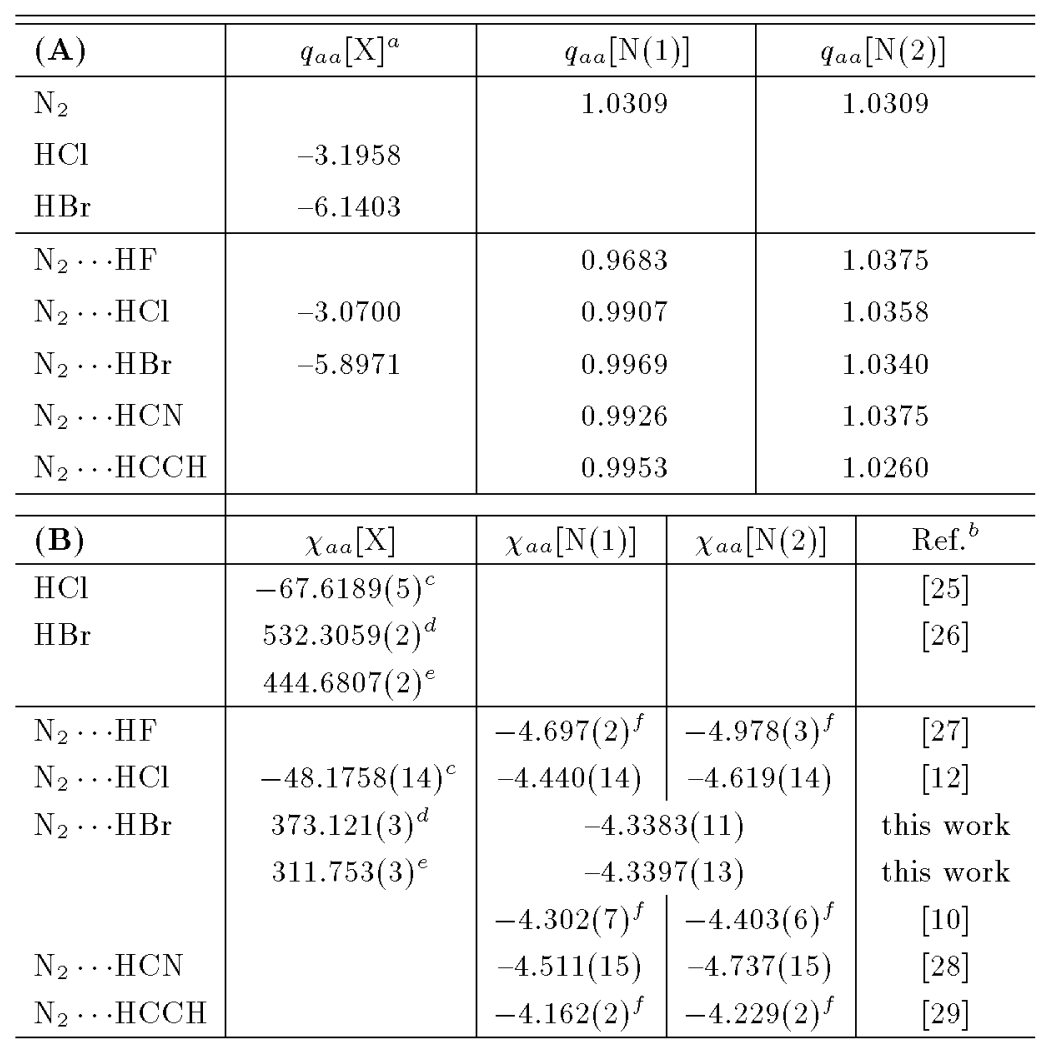

${ }^{a} \mathrm{X}=\mathrm{Cl}$ or $\mathrm{Br}$ in the proton donor molecule.

${ }^{b}$ The source of experimental values of nuclear quadrupole splitting constants $\chi$.

${ }^{c}$ For ${ }^{35} \mathrm{Cl} .{ }^{d}$ For ${ }^{79} \mathrm{Br} .{ }^{e}$ For ${ }^{81} \mathrm{Br}$. ${ }^{f}$ Values for ${ }^{14} \mathrm{~N}^{15} \mathrm{~N}$ isotopomers.

systematic underestimate of the field gradient by the basis [30], as well as for the vibrational averaging, was made with

$$
\begin{aligned}
\chi(\mathrm{Br})^{\mathrm{N}_{2} \mathrm{HBr}} & =\frac{1}{2}\left(3 \cos ^{2} \phi-1\right) \chi(\mathrm{Br})^{\mathrm{HBr}} q_{a a}(\mathrm{Br})^{\mathrm{N}_{2} \mathrm{HBr}} / q_{a a}(\mathrm{Br})^{\mathrm{HBr}}, \\
\chi\left(\mathrm{N}_{i}\right)^{\mathrm{N}_{2} \mathrm{HBr}} & =\frac{1}{2}\left(3 \cos ^{2} \theta-1\right) \chi(\mathrm{N})^{\mathrm{N}_{2}} q_{a a}\left(\mathrm{~N}_{i}\right)^{\mathrm{N}_{2} \mathrm{HBr}} / q_{a a}(\mathrm{~N})^{\mathrm{N}_{2}},
\end{aligned}
$$

where the quantities $q_{a a}=\partial^{2} V / \partial a^{2}$ are the calculated field gradients at the respective nuclei. Thus Eq. (5) was used to determine $\phi(\mathrm{HBr})$, but $\theta\left(\mathrm{N}_{2}\right)$ could not be directly determined from Eq. (6) because of uncertainty in the value of $\chi(\mathrm{N})$ for the free nitrogen molecule. Instead we have used the standard single isotopic 
substitution equations of Kraitchman [31] to evaluate the $r_{s}$ bond length of the $\mathrm{N}_{2}$ molecule in the dimer, as has been carried out for [32]. This bond length would primarily be the subject of large amplitude averaging, $r_{s}=r_{0}^{\mathrm{N}_{2}} \cos \theta$, from which $\theta$ can be evaluated.

Comparison of the derived quantities listed in Table III shows excellent agreement among the various isotopomers and the small differences are readily rationalisable. The averaging angles in Table III, are close to $\theta=20.05^{\circ}$ and $\phi=25.45^{\circ}$ determined in [10], although the present values are preferred owing to the use of considerably fewer assumptions. The fact that the employed models are still satisfactory for $\mathrm{N}_{2} \cdots \mathrm{HBr}$ is quite important since the next higher dimer in the series, between $\mathrm{N}_{2}$ and $\mathrm{HI}$, is no longer bonded through the hydrogen, but appears to have the $\mathrm{N}_{2} \cdots$ IH geometry at the global minimum [33]. There is therefore a considerable increase in anharmonicity in the intermolecular potential due to two competing linear forms. Figure 3 shows a comparison of two independently evaluated model parameters, made for several linear dimers of $\mathrm{N}_{2}$ bound through the $\mathrm{H}$ atom. There is, indeed, increasing noise with decreasing strength of the intermolecular interaction.

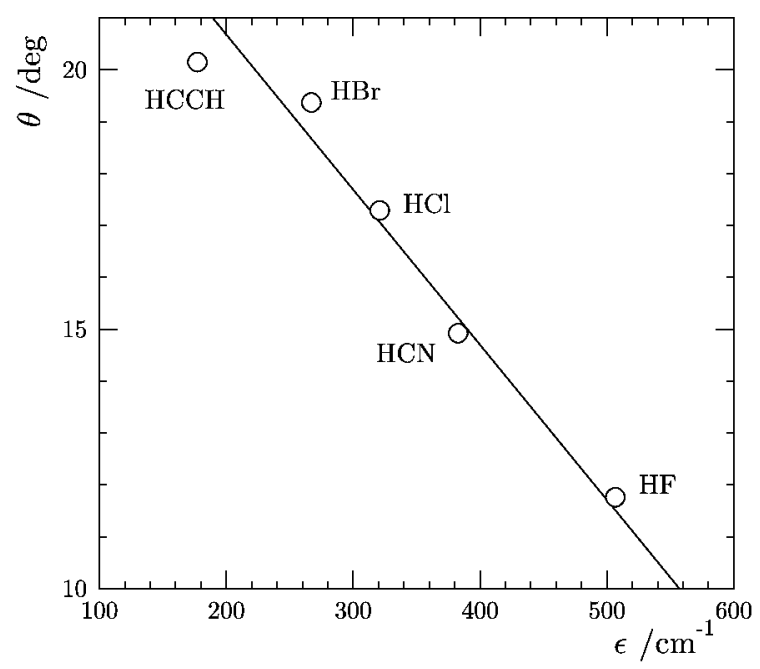

Fig. 3. The correlation between the large amplitude oscillation angle for nitrogen in linear dimers and the Lennard-Jones well depth in the diatomic approximation.

The presently reported new experimental information and modified analysis allow a revised spectroscopic evaluation of the elusive nuclear quadrupole splitting constant of the isolated nitrogen molecule. Two previous attempts from supersonic expansion studies have been made. Analysis of results for $\mathrm{N}_{2} \cdots \mathrm{HCCH}$ and $\mathrm{N}_{2} \cdots \mathrm{HCN}$ gave $\chi(\mathrm{N})=-5.01(13)$ and $-5.07(8) \mathrm{MHz}$, respectively [32], while those for $\mathrm{N}_{2} \cdots$ Ar led to $\chi(\mathrm{N})=-5.528(27) \mathrm{MHz}$ [16]. These numbers can be compared with the librationally decoupled NQR value for solid nitrogen of 
TABLE V

Determination of the nuclear quadrupole splitting constant, $\chi(\mathrm{N})$, for free dinitrogen.

\begin{tabular}{l|c|c|c}
\hline \hline & $\begin{array}{c}\chi_{a a}(\mathrm{~N}) \text { in dimer } \\
\\
\end{array}$ & $\begin{array}{c}\theta(\mathrm{MHz} \\
/ \mathrm{Neg}\end{array}$ & $\begin{array}{c}\chi_{a a}(\mathrm{~N}) \text { in } \mathrm{N}_{2} \\
/ \mathrm{MHz}\end{array}$ \\
\hline $\mathrm{N}_{2} \cdots \mathrm{HF}$ & -4.838 & 11.84 & -5.31 \\
$\mathrm{~N}_{2} \cdots \mathrm{HCl}$ & -4.530 & 17.37 & -5.32 \\
$\mathrm{~N}_{2} \cdots \mathrm{HBr}$ & -4.338 & 19.45 & -5.29 \\
$\mathrm{~N}_{2} \cdots \mathrm{HCN}$ & -4.624 & 14.92 & -5.22 \\
$\mathrm{~N}_{2} \cdots \mathrm{HCCH}$ & -4.195 & 20.15 & -5.21 \\
\hline
\end{tabular}

${ }^{a}$ The mean of $\chi_{a a} \mathrm{~N}(1)$ and $\chi_{a a} \mathrm{~N}(2)$.

$-5.39(5) \mathrm{MHz}$ [34]. Presently we can combine the estimate of $\theta$ from isotopic substitution with contemporary ab initio field gradients and use Eq. (6) to reevaluate such values for the most studied complexes of $\mathrm{N}_{2}$. The results are listed in Table $\mathrm{V}$ and have been derived by using field gradients and coupling constants a veraged over the two dinitrogen nuclei in the complex. Two groups of values can be discerned in Table $\mathrm{V}$. The values from the three $\mathrm{N}_{2} \cdots \mathrm{HX}$ dimers are close together with a mean at $-5.31 \mathrm{MHz}$. The values for dimers to the two longer stick molecules, $\mathrm{N}_{2} \cdots \mathrm{HCN}$ and $\mathrm{N}_{2} \cdots \mathrm{HCCH}$ are now, unlike in [32], rather close together and of rather higher magnitude. They are, however, significantly below the three values for dimers with the hydrogen halides. We would anticipate that the more extended dimers to the longer proton donor molecules would be more susceptible to departure from the diatomic-based models used here. On the basis of the results in Table $\mathrm{V}$ we therefore estimate the nitrogen nuclear quadrupole splitting constant for free nitrogen to be $-5.3(1) \mathrm{MHz}$. This is in agreement with the solid state value, and straddles the two previous, mutually inconsistent spectroscopic determinations. Although we have followed the general principles used in [32] we believe that we have improved the reliability of evaluation by dispensing with several intermediate assumptions and model calculations of the electric fields. As for the high value from $\mathrm{N}_{2} \cdots \operatorname{Ar}[16]$ this is based on the value of $\chi_{c e}$ for the dimer and the assumption that it is insensitive to vibration-rotation contributions. Nevertheless, that assumption does not seem to hold particularly well, even in the light of results in Table II of [16], since the effective fits for the two $K_{a}=1$ states lead to two rather different values of $\chi(\mathrm{N})=-5.514(8)$ and $-5.370(3) \mathrm{MHz}$. The value $-5.528(27)$ results from a global fit, which does not reconcile the discrepancy noted above. We note, however, that the lower of the two $K_{a}=1$ values is actually consistent with the present determination. 


\section{Acknowledgments}

We are grateful to dr M.J. Nowak for the sample of $\mathrm{HBr}$ and acknowledge financial support from the Institute of Physics and from the State Committee for Scientific Research, grant KBN-3T09A-126-17.

\section{References}

[1] N. Pugliano, R.J. Saykally, Science 257, 1937 (1992).

[2] M.R. Viant, M.G. Brown, J.D. Cruzan, R. Saykally, M. Geleijns, A. van der Avoird, J. Chem. Phys. 110, 4369 (1999), and references cited therein.

[3] S. Re, Y. Osamura, S. Youhei, H.F. Schaefer III, J. Chem. Phys. 109, 973 (1998); S. Re, J. Phys. Chem. A 105, 9725 (2001).

[4] A. Milet, C. Struniewicz, R. Moszynski, P.E.S. Wormer, J. Chem. Phys. 115, 349 (2001)

[5] Z. Kisiel, B.A. Pietrewicz, P.W. Fowler, A.C. Legon, E. Steiner, J. Phys. Chem. A 104, 6970 (2000).

[6] Z. Kisiel, E. Białkowska-Jaworska, L. Pszczółkowski, A. Milet, C. Struniewicz, R. Moszynski, J. Sadlej, J. Chem. Phys. 112, 5767 (2000).

[7] Z. Kisiel, J. Kosarzewski, B.A. Pietrewicz, L. Pszczółkowski, Chem. Phys. Lett. 325, 523 (2000).

[8] Z. Kisiel, B.A. Pietrewicz, A. Suckley, A.C. Legon, to be published.

[9] Z. Kisiel, B.A. Pietrewicz, L. Pszczółkowski, I. Struniewicz, J. Sadlej, to be published.

[10] N.W. Howard, A.C. Legon, J. Chem. Phys. 90, 672 (1989).

[11] Z. Kisiel, J. Kosarzewski, L. Pszczółkowski, Acta. Phys. Pol. A 92, 507 (1997).

[12] Z. Kisiel, L. Pszczółkowski, P.W. Fowler, A.C. Legon, Chem. Phys. Lett. 276, 202 (1997).

[13] H.M. Pickett, J. Mol. Spectrosc. 148, 371 (1991).

[14] H.M. Pickett, http://spec.jpl.nasa.gov/ftp/pub/calpgm.

[15] Z. Kisiel, PROSPE - Programs for ROtational SPEctroscopy, http://info.ifpan.edu.pl/ ${ }^{\circ} \mathrm{kisiel} / \mathrm{prospe} . \mathrm{htm}$.

[16] W. Jäger, M.C.L. Gerry, Chem. Phys. Lett. 196, 274 (1992).

[17] A. Ernesti, J.M. Hutson, J. Chem. Phys. 101, 5438 (1994).

[18] J. Bendtsen, J. Raman. Spectrosc. 2, 133 (1974).

[19] F.C. De Lucia, P. Helminger, W. Gordy, Phys. Rev. A 3, 1849 (1971).

[20] D.J. Millen, Can. J. Chem. 63, 1477 (1985).

[21] M.R. Keenan, E.J. Campbell, T.J. Balle, L.W. Buxton, T.K. Minton, P.D. Soper, W.H. Flygare, J. Chem. Phys. 72, 3070 (1980).

[22] T.H. Dunning, Jr., J. Chem. Phys. 90, 1007 (1989); R.A. Kendall, T.H. Dunning, Jr., R.J. Harrison, J. Chem. Phys. 96, 6796 (1992). 
[23] M.W. Schmidt, K.K. Baldridge, J.A. Boatz, S.T. Elbert, M.S. Gordon, J.H. Jensen, S. Koseki, N. Matsunaga, K.A. Nguyen, S.J. Su, T.L. Windus, M. Dupuis, J.A. Montgomery, J. Comput. Chem. 14, 1347 (1993).

[24] Z. Kisiel, E. Białkowska-Jaworska, L. Pszczółkowski, J. Chem. Phys. 109, 10263 (1998).

[25] E.W. Kaiser, J. Chem. Phys. 53, 1686 (1970).

[26] O.B. Dabbousi, W.L. Meerts, F.H. de Leeuw, A. Dymanus, Chem. Phys. 2, 473 (1973).

[27] P.D. Soper, A.C. Legon, W.G. Read, W.H. Flygare, J. Chem. Phys. 76, 292 (1982).

[28] E.J. Goodwin, A.C. Legon, J. Chem. Phys. 82, 4434 (1985).

[29] A.C. Legon, A.L. Wallwork, P.W. Fowler, Chem. Phys. Lett. 184, 175 (1991).

[30] A. Halkier, M. Jaszunski, P. Jorgensen, Phys. Chem. Chem. Phys. 1, 4165 (1999).

[31] W. Gordy, R.L. Cook, Microwave Molecular Spectra, Wiley, New York 1984.

[32] A.C. Legon, P.W. Fowler, Z. Naturforsch. A 47, 367 (1992).

[33] W. Jabs, A.L. McIntosh, R.R. Lucchese, J.W. Bevan, D.J. Brugh, R.D. Suenram, J. Chem. Phys. 113, 249 (2000).

[34] T.A. Scott, Phys. Rep. C 27, 89 (1976). 